\title{
SURGICAL TREATMENT OF PREMATURE SAGITTAL SYNOSTOSIS
}

\author{
GERALDO PIANETTI*
}

\begin{abstract}
A series of 50 consecutive children with premature sagittal synostosis is reported. All were treated surgically; 43 were male, 47 were leukodermic and two are siblings. In the pre-operative examination, the head shape, skull measurements and radiologic findings were evaluated; 38 children were operated on before six months of age and 12 of them, between six and 12 months of age. The surgical technique used was a wide biparietal craniectomy. Blood transfusions were occasional, being necessary for only six (12\%) children. The children were admitted at the day of surgery and discharged between the second and the third post-operative day. No local or general complications were observed and no one died. The aesthetic result was considered good. The altered skull measurements before surgery reached normalization as far as the end of the first year after the treatment. It may be concluded that wide biparietal craniectomy is a procedure of great effectiveness in the treatment of the premature fusion of the sagittal suture.
\end{abstract}

KEY WORDS: craniosynostosis, sagittal suture.

\section{Tratamento cirúrgico da fusão prematura da sutura sagital}

RESUMO - É apresentada uma série de 50 crianças com fusão isolada e prematura da sutura sagital, tratadas cirurgicamente; 43 eram do sexo masculino, 47 leucodérmicas e duas irmās. No pré-operatório foram avaliados o formato da cabeça, medidas do crânio e medidas radiológicas, 38 crianças foram operadas antes dos 6 meses de idade e 12 entre os 6 e 12 meses. A técnica cirúrgica usada foi a craniectomia parcial, ampla e biparietal. A transfusão sanguínea foi eventual, sendo necessária em somente 6 crianças (12\%). As crianças foram admitidas no dia da cirurgia e receberam alta entre o segundo e terceiro dia após a cirurgia. Não foram observadas complicações locais ou gerais e não houve óbito. $O$ resultado estético final foi considerado bom; as medidas do crânio, alteradas antes da cirurgia, se normalizaram até um ano após o tratamento. Conclui-se que a craniectomia parcial, ampla e biparietal é eficiente no tratamento da fusão isolada e prematura da sutura sagital, até o primeiro ano de vida.

PALAVRAS-CHAVE: craniossinostose, sutura sagital.

The first papers concerning the surgical treatment of premature craniosynostosis were already published in the last century ${ }^{17,18}$. Nevertheless, as recently as the middle of the twentieth century, the surgical treatment of the premature fusion of the sagittal suture faced a strong resistance among experts. Since Faber and Towne (1943) ${ }^{9}$, Simmons and Peyton (1947) ${ }^{26}$, Ingraham and cols. (1948) many techniques have been proposed for the surgical correction of this malformation. It is already universally accepted that children having such a deformity should be treated early by surgical correction. The most used surgical techniques are the linear craniectomy with placement of

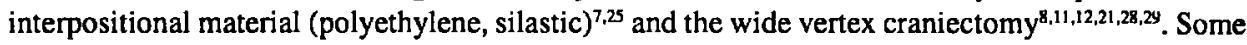
surgeons use wire to reduce the length of the skull ${ }^{1,15,30}$ or multiple cauterization of the dura mater ${ }^{4}$ or else the treatment of the dura mater with Zenker solution ${ }^{2,22}$. In children older than two years and having great skull deformity, a reconstruction of the verte ${ }^{27}$ or more invasive techniques are recommended, sometimes with bone transposition ${ }^{13,19}$.

Division of Neurosurgery, Hospital das Clinicas, Faculty of Medicine Federal University of Minas Gerais (UFMG), Hospital São Francisco de Assis, Belo Horizonte, Brazil: *M.D., M.S.C., Associate Professor. Aceite: 2-abril-1997.

Dr. Geraldo Pianetti - Rua dos Aimorés 2480/902 - 30140-072 Belo Horizonte MG - Brasil. 


\section{MATERIAL AND METHODS}

The children analysed here are part of an author's series of 104 patients with craniosynostosis.

The children were operated on at the Division of Paediatric Neurosurgery of the Hospital São Francisco and Hospital das Clínicas in Belo Horizonte, Brazil, from January-1980 to December-1995.

Fifty $(48 \%)$ children presented a premature and isolated fusion of the sagittal suture. Forty-three children (86\%) were male and seven (14\%) were female. Forty-seven children (94\%) were white and only three (6\%) were black. Two were siblings. Among the other 48 there were no familial cases. Age at operation ranged from one to twelve months (average 6.3); 38 children (76\%) were younger than six months of age.

Clinical signs or symptoms of high intracranial pressure were not observed and only one child had another associated malformation (Pierre-Robin syndrome). Twenty-three (46\%) were diagnosed at birth and, in one of them, premature fusion of the sagittal suture was observed before birth, through ultrasonography. Three children presented seizures; one had a familial history of epilepsy.

On examination, the children always exhibited an abnormal shaped head which was scaphocephalic, sometimes with marked frontal bossing or/and an occipital bulge. Thirty-nine children (78\%) had a palpable bony ridge along the sagittal suture and in $18(36 \%)$ the anterior fontanel was oped at palpation. Ocular aiterations were not observed. Six children presented a head circumference above the 98 percentile. The cephalic index ${ }^{n}$ ranged from 0.62 to 0.91 with the average of 0.81 . In 42 children (84\%) a cephalic index below normal was found, between 0.62 and 0.87 (average of 0.79 ). The other eight had a cephalic index of 0.89 on average.

In every child, the plain skull $X$-ray films confirmed the premature fusion of the sagittal suture and the scaphocephalic head shape. In a particular child more proeminent digitiform impressions were observed, in spite of no symptoms of intracranial hypertension. Thirty-six children (72\%) underwent a CT scan. All of them were considered normal in relation to the brain, showed the scaphocephalic head shape and some of them showed a parasutural sclerosis on both sides of the ossified suture and an external or internal bony ridge along the suture.

The pre-operative hematocrit ranged from $31 \%$ to $34 \%$. evaluation.

Surgery was performed as early as possible following the neurosurgical diagnosis and the clinical-laboratory

Surgery consisted of a wide biparietal craniectomy that was carried across the coronary and lambdoid sutures. With the patient under general endotracheal anesthesia, a peripheral venous catheter was placed and a single dose of a broad-spectrum antibiotic was administered. It was important that the endotracheal tube would be fixed properly. The four limbs were wrapped in orthopedic cotton to keep the child warm. The child was placed in a prone position, with the head slightly extended and resting on a padded horseshoe headrest, leaving the vertex exposed from the frontal to the occipital region. Special care was taken to avoid pressure on the forehead and the eyes. Subcutaneous infiltration with epinephrine solution was used. The skin midline incision started at the external occipital protuberance and extended so far as the anterior region of the bregmatic fontanele, allowing visualization of the coronary, sagittal and lambdoid sutures and the parietal bones in almost all its extension. The scalp incision was performed gradually followed by hemostasis with coagulation of the blood vessels and preventive stitches placed at the borders of the incision line. After the vertex exposition, two burr holes were placed in front of the lambdoid suture two centimeters lateral to the midline. Afterwards, with the help of delicate rongeurs, a wide biparietal craniectomy was performed, passing the coronary and lambdoid sutures by about one centimeter. Before each small resection, a gentle displacement of the dura was achieved with microdissector. When necessary, the occiput was removed. The last bone removed was that which covered the superior sagittal sinus next to the lambdoid suture, easily detached with the help of the microdissector. The dura mater exposure was six to eight centimeters wide. Bleeding of the superior sagittal sinus was rarely a problem and when it happened it was easily controlled with bipolar and absorbent hemostatic. During all the surgical procedure, hemostasis was obtained with bone-wax, bipolar cauterization and gauze soaked with peroxide; bleeding was minimum, avoiding, this way, blood transfusions. The skin was closed with monofilament nylon. No drain was used. Compressive head dressing was applied and kept in place for 48 hours.

\section{RESULTS}

In spite of aesthetic results having justified the surgery in all children, it was observed that the surgery was easier and faster when performed in children before six months of age. In these cases, the skull shape normalization was more precocious, sometimes in the first $\mathbf{3 0}$ days after surgery. 
Blood replacement was necessary in six of the 50 children. Three of them received intraoperative blood transfusion and three others soon after the operation.

An early discharge was one of our aims. The mean length of total hospitalization was 2.62 days (ranged from two to four days); 37 children (74\%) were in hospital for 48 hours, nine (18\%) for 72 hours and four (8\%) more than 72 hours.

No complication concerning the surgical procedure was observed. There were no deaths.

All the children have been followed for more than one year ( 1 to 12 years; average of 3.9 years). Cosmetic results were analysed by the skull shape, the aspect of the scar, head measurements and skull radiologic study. The subjetive observation was done by the parents, pediatricians and the surgeon. All patients had excellent cosmetic results. In spite of showing a tendency to the normalization of the skull shape soon after the surgical treatment, it became sometimes difficult to define aesthetic results before six months after surgery. There were no problems in relation to the scar, always longitudinal, along the line of the sagittal suture and covered in its total extention by hair.

An increase in the biparietal diameter was observed in all cases. The cephalic index that was inferior to the minimum in $84 \%$ of the children before surgery (average of 0.79 ), became normal in $89 \%$ of them (average of 0.91 ). Post-operative skull $X$-rays showed that the reossification was complete within one year.

It was difficult to the surgeon to evaluate such results as "very good", "good" and "regular", and for this reason this criterion was not used. The evaluation was subjective and it was conditioned to other quite different factors which were not intimately related to the structure of the skull. Among other variables that could influence a favorable observation were: skin color, kind and length of the hair, facial appearance, eye colors, face harmony, inheritance. There was yet the cultural factor that, according to some people it was taken as an agreable aspect and to others it is not, when one compares the obtained result with the ethnia aesthetic.

\section{DISCUSSION}

The surgical technique used in all the 50 children, since 1980 , characterized by wide biparietal craniectomy, without interpositional material or application of Zenker's solution to the dura mater, corresponds to that described by Epstein and coworkers ${ }^{8}$. The concept that surgery must be indicated earlier appears since Dandy (1943) ${ }^{5}$. Most of the authors agree that the surgical correction must be

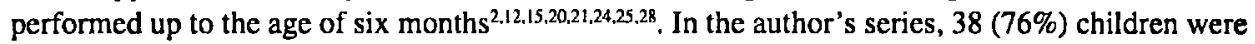
operated on before the sixth month of life, $30(60 \%)$ before the fourth month of life. Surgical indication after the first year of life is controversial since the main objective of surgery is aesthetic, but if it is necessary due to intracranial hypertension or psychological problems, other more traumatic techniques are indicated $\mathbf{f}^{5.13 .19 .23}$.

Some authors state that the isolated and premature fusion of the sagittal suture may compromise the normal development of the brain; in cases that it is not treated surgically intracranial hypertension, delay in the neuro-psycho-motor development, ocular disturbs or even mental retard may occur ${ }^{5,9,23 .}$ Nevertheless it is not possible to establish a close relationship between these alterations and the skull malformation ${ }^{3}$. Other authors ${ }^{3,10-12,23-25}$ present important data showing that when operation is not performed, the child may develop psychological conflicts, that interfere with good school performance. There could also be a high incidence of anxiety among the parents and children. There are many reports where parents show their regret for not having authorized treatment ${ }^{3,11}$. In these series, parents were invariably pleased with the surgical results.

The goal of the early treatment is the restoration of the aesthetic of the skull. This will prevent emotional disturbance and probably late functional alterations. In all cases the surgeon expressed to 
the parents his opinion that the treatment should be surgical, but also let them know of the possibility of such a child growing without brain damage if not operated on. Using the technique of the wide craniectomy, bone growth will take place between six months and one year after surgery, time enough for the skull measurements (antero-posterior and side to side distances) reach its ideal limits. Thus, it is not justified the interposition of plastic material (polyetilene ${ }^{3,20,25}$, silastic $^{7,24}$, metilmetacrilate ${ }^{10}$, rubber $^{16}$ ); the use of chemical substance on the dura mater (Zenker's solution or iodated alcohol ${ }^{2,22}$ ); dissection of the dural external layer ${ }^{4}$; coagulation of the dura mater ${ }^{4}$ or more refined techniques with the use of microplates, struts, screws or reshaping of the skull with bone grafts ${ }^{11,15,19,23,30}$. These techniques increase the number of complications. Blood transfusion in six children (12\%) contrasts with the literature which shows the use of blood in $50 \%$ to $100 \%$ of the children who were operated on $2.8 .11 .12 .15 .20,21.24 .25,28-30$.

In the author's personal experience, the average time of surgery is 68.64 minutes, and in $90 \%$ of times it reached 60 minutes. Similar periods of time are reported by Greene and Winston" with the average of 55 minutes. On the other side, Vollmer and coworkers ${ }^{30}$ relate an average of 90 minutes, Hassler and Zentner ${ }^{12}$ of 120 minutes and Jane and coworkers ${ }^{15}$ of 150 minutes.

The short time of hospitalization is important, chiefly among us because it decreases costs and reduces the risk of hospital infection. In the literature, an average of nine days is observed ${ }^{1.10-}$ $12,21,29,30$, compared to an average of 2.62 days in this series.

The literature is full of reports of complications concerning the surgical treatment of the craniosynostosis, such as anemia ${ }^{20.25 .27 .28}$, scalp necrosis ${ }^{20.23 .25}$, infection ${ }^{27.16 .20 .21 .25 .27 .28}$, sub galeal collection $^{30}$, sub dural hematoma ${ }^{23,25,27}$, motor deficit ${ }^{28}$, heart failure ${ }^{2,25}$, bone necrosis ${ }^{25}$, seizures $^{22,25}$, sagittal sinus rupture ${ }^{21}$, wire extrusion ${ }^{5,30}$, brain edema ${ }^{4}$, cerebral spinal fluid leakage ${ }^{4,25}$ and death ${ }^{13,22,25}$. Most of these complications took place in surgeries where interposition material, dissection of the external layer of the dura, Zenker's solution were used, or longer surgeries. In the present series there were no complications or deaths. The same was observed by Barritt and coworkers ${ }^{3}$ and Hassler and Zentner' ${ }^{12}$.

The clinical and radiological follow-up is necessary, at least, during the first year after surgery, with the objective of observing the aesthetic, the normalization of the skull measures and bone growth. The author considers the personal observation as the starting and major point in the final assessment of the aesthetic result. In none of the 50 children operated on, reoperation on the skull was considered necessary to make the skull look better, to remake the craniectomy or to correct persisting bone defects.

\section{CONCLUSIONS}

In the analysis of the surgical experience on the premature and isolated fusion of the sagittal suture, one concludes that treatment must be performed using a wide biparietal craniectomy, without the use of interpositional material or chemical solutions on the dura; it must be performed up to the sixth month of age; blood reposition should be occasional and not the rule; discharge from hospital may occur early; the aesthetic evaluation should be done by parents, pediatrician and surgeon's observation; the skull measurements, generally alterated before the treatment, come to normalization within 12 months. In the present series no complications or deaths were observed.

\section{REFERENCES}

1. Albright AL. Operative normalization of skull shape in sagittal synostosis. Neurosurgery 1985;17:329-331.

2. Anderson FM, Geiger L. Craniosynostosis: a survey of 204 cases. J Neurosurg 1965;2:229-240.

3. Barritt J, Brooksbank M, Simpson D. Scaphocephaly; aesthetic and psychosocial considerations. Dev Med Child Neurol 1981;23:183-19].

4. Czorny A, Chocron S, Forlodou P, Tisserant D, Striker M, Montaut J. Scaphocéphalies: traitement et complications: à propos de 115 cas. Neurochirurgie 1987;33:190-195. 
5. Dandy WE. An operation for scaphocephaly. Arch Surg 1943;47:247-249.

6. Diament AJ. Um novo índice cefálico no primeiro ano de vida. Rev Paul Med 1968;72:303-305.

7. Duff TA, Mixter RC. Midline craniectomy for sagittal suture synostosis: comparative efficacy of two barries to calvarial reclosure. Surg Neurol 1991;35:350-354.

8. Epstein N, Epstein F, Newman G. Total vertex craniectomy for the treatment of scaphocephaly. Child's Brain 1982;9:309-316.

9. Faber HK, Towne EB. Early operation in premature cranial synostosis for the prevention of blindness and other sequelae. J Pediatr 1943;22:286-307.

10. Foltz EL, Loeser JD. Craniosynostosis. J Neurosurg 1975;43:48-56.

11. Greene CS, Winston KR. Treatment of scaphocephaly with sagittal craniectomy and biparietal morcellation. Neurosurgery 1988;23:196-202.

12. Hassler W, Zentner J. Radical osteoclastic craniectomy in sagittal synostosis. Neurosurgery 1990;27:539-543.

13. Hudgins RJ, Burstein FD, Boydston WR. Total calvarial reconstruction for sagittal synostosis in older infants and children. J Neurosurg 1993;78:199-204.

14. Ingraham FD, Alexander E, Matson DD. Clinical studies in craniosynostosis: analysis of fifty cases and description of a method of surgical treatment. Surgery 1948;24:518-541.

15. Jane JA,.Edgerton MT, Futrell JW, Park TS. Immediate correction of sagittal synostosis. J Neurosurg 1978;49:705-710.

16. Keener EB. Experimental observations on the use of rubber in the treatment of craniosynostosis. J Neurosurg 1958;15:642-652.

17. Lane LC. Pioneer craniectomy for relief of mental imbecility due to premature sutural closure and microcephalus. J Am Med Assoc 1892;18:49-50.

18. Lannelongue M. De la craniectomie dans la microcéphalie. CR Acad Sciences 1890;110:1382-1386.

19. Marsh JL, Jenny A, Galic M, Picker S, Vannier MW. Surgical management of sagittal synostosis. Neurosurg Clin North Am 1991;2:629-640.

20. McLaurin RL, Matson DD. Importance of early surgical treatment of craniosynostosis. Pediatrics 1952;10:637-652.

21. Olds MV, Storrs B, Walker ML. Surgical treatment of sagittal synostosis. Neurosurgery 1986;18:345-347.

22. Pawl PP, Sugar O. Zenker solution in the surgical treatment of craniosynostosis. J Neurosurg 1972;36:604-607.

23. Samra KA, Sorour O. Bilateral flap operation for craniosynostosis.J Neurosurg 1968;29:591-596.

24. Shillito J. A plea for early operation for craniosynostosis. Surg Neurol 1992;37:182-188.

25. Shillito J, Matson DD. Craniosynostosis: a review of 519 surgical patients. Pediatrics 1968;41:829-853.

26. Simmons DR, Peyton WT. Premature closure of the cranial sutures. J Pediatr 1947;31:528-547.

27. Sorour $O$. The four-flap operation: a new operation for treatment of craniosynostosis. J Neurosurg 1961;18:86-90.

28. Stein SC, Schut L. Management of scaphocephaly. Surg Neurol 1977;7:153-155.

29. Venes JL, Sayers MP. Sagittal synostectomy. J Neurosurg 1976;44:390-392.

30. Vollmer DG, Jane JA, Park TS, Persing JA. Variants of sagittal synostosis: strategies for surgical corretion. J Neurosurg $1984 ; 61: 557-562$. 